\title{
A new approach in skin effect and storativity estimation from pumping test data with low pumping rates
}

\author{
Jakub Nedvěd \\ Charles University in Prague, Faculty of Science, Department of Applied Geology; Albertov 6, 12800 Prague 2, \\ Czech Republic;e-mail:nedvedj@natur.cuni.cz \\ (C) 2016 Authors. This is an open access publication, which can be used, distributed and reproduced in any medium according \\ to the Creative Commons CC-BY 4.0 License requiring that the original work has been properly cited.
}

Pumping test are supposed to be one of the best ways of determining hydraulic parameters of examined aquifer. However, there are many other effects which control measured drawdown in a wellbore. One of the major effects is well clogging and well storage. Well clogging (also called skin effect (van Everdingen 1953)) causes additional drawdown in the well and well storage (Papadopulos \& Cooper 1967) causes distortion of data in the first part of pumping test. The author shows that both these effects can be estimated from measured drawdown when two special approaches are used - first, the drawdown must be measured at very short intervals (0.5-1.0 second), and second, the pumping rates must be rather low, so the examined aquifer is not stressed enough (the drawdown in the aquifer is very small) and the skin effect/well storage influence is more significant in this case. This approach also eneables the interpreter to estimate more exact storativity coefficient, because evaluation of skin effect leads to better wellbore screen hydraulic losses estimation. Hydraulic losses caused by wellbore skin leads to the shift of Jacob's line (Cooper \& Jacob 1946) which is connected with storativity misinterpretation. A formula for eliminating this problem is also presented. Using this formula can help to estimate storativity coefficient by using measured data from pumped well. Drawdown measured in pumped well is rarely used for storativity interpretation precisely because of wellbore clogging. The formula partly eliminates that problem. In the end, application of presented approach is shown on several pumping test conducted in very permeable sand - gravel quaternary sediments of the Jizera River and the Elbe River. The pumping tests are first interpreted by casual methods - Theis (1935) and/or Moench (1997) - and then the new presented method is used. It is shown that closer to real values of storativity are gained when the newly derived formula is taken into account.

\section{REFERENCES}

Cooper H.H. \& Jacob C.E., 1946. A generalized graphical method for evaluating formation constants and summarizing well field history. Transactions, American Geophysical Union, 27, 526-534.

Everdingen A.F. van, 1953. The skin effect and its influence on the productive capacity of a well. Petroleum Transaction, AIME, 198, 171-176.

Moench A.F., 1997. Flow to a well of finite diameter in a homogenous, anisotropic water table aquifer. Water Resources Research, 33, 6, 1397-1407.

Papadopulos I.S \& Cooper H.H., 1967. Drawdown in a well of large diameter. Water Resources Research, 3, 1, 241-244.

Theis Ch.V., 1935. The relation between the lowering of the piezometric surface and the rate and duration of discharge of a well using groundwater storage. Transactions, American Geophysical Union, 16, 519-524. 